\title{
Role of Sodium Glucose Co-Transporter-2 Inhibitors in Pre-diabetes and Their Extra-glycemic Effects
}

\author{
Hala Ahmadieh ${ }^{1}$, Nisrine Ghazal ${ }^{2}$, Sami Azar ${ }^{3}$
}

\section{Abstract}

The burden of diabetes mellitus and pre-diabetes has been extensively increasing over the past few years. Selective sodium-glucose co-transporters inhibitors were extensively studied in type 2 diabetes mellitus and were found to have sustained urinary glucose loss, improvement in glycemic control, in addition to their proven metabolic effects. Although they sound to be promising, there is still no clear data regarding their use in the prevention of diabetes, in pre-diabetic individuals, a subset of patients who are at increased risk of development of type II diabetes and its complications. Moreover, sodium-glucose co-transporters inhibitors were found to have multiple extra-glycemic beneficial effects, including weight loss, blood pressure reduction and beneficial effects on the kidneys. Therefore, their use in pre-diabetes is postulated to be beneficial on glucose and metabolic profile and larger studies need to be conducted in this subset of population.

\section{Keywords}

Diabetes Mellitus, Pre-Diabetes, Sodium-Glucose Co-Transporters, Oral Diabetic Medications, Weight Loss, Cardiovascular Events.

\section{Introduction}

Tight glucose homeostasis is adequately maintained in healthy individuals through the regulation of glucose production, reabsorption, and utilization. Therefore, despite extreme variations in glucose intake, relatively few people develop diabetes or hypoglycemia. Moreover, in healthy individuals about 180 grams of glucose is filtered daily by the renal glomeruli, and is then reabsorbed in the proximal convoluted tubules (PCT), through the help of the passive facilitated glucose transporters (GLUTS), and the active, sodium-glucose co-transporters

1 Senior Lecturer, Clinical Science Department of Internal Medicine, Beirut Arab University, Beirut, Lebanon.

2 Clinical Fellow of Endocrinology, Department of Endocrinology and metabolism, American University of Beirut, Beirut, Lebanon.

3 Professor, Department of Internal Medicine, Division of Endocrinology, American University of Beirut, New York, United States.

Contact information:

Sami T. Azar, MD, FACP.

Address: Department of Internal Medicine, Division of Endocrinology, American University of Beirut 3 Dag Hammarskjold Plaza, 8th Floor, New York, NY 10017, United States.

Tel.: 009613234250.

Fax: 009611744703.

” sazar@aub.edu.lb 
Table 1. Comparison between SGLT1 versus SGLT2.

\begin{tabular}{|c|c|c|}
\hline Characteristics & SGLT 1 & SGLT 2 \\
\hline Location & $\begin{array}{l}\text { Apical membrane of small intestine absorptive cells } \\
\text { (Enterocytes); later part of PCT (Segment 3) SGLT1 can also be } \\
\text { located in the brain, skeletal muscle, lungs, liver, and kidney. }\end{array}$ & $\begin{array}{l}\text { Exclusively found in the apical } \\
\text { membrane of renal convoluted } \\
\text { proximal tubules (S1 and S2) }\end{array}$ \\
\hline Capacity & Low capacity & High Capacity \\
\hline Affinity & High affinity & Low Affinity \\
\hline $\begin{array}{l}\text { Contribution to glucose } \\
\text { reabsorption }\end{array}$ & $<10 \%$ & More than $90 \%$ \\
\hline $\begin{array}{l}\text { Disease state if mutation/ } \\
\text { deficiency occurs }\end{array}$ & $\begin{array}{l}\text { Potentially fatal neonatal condition of glucose galactose } \\
\text { malabsorption }\end{array}$ & Familial renal glucosuria \\
\hline \multirow[t]{2}{*}{$\begin{array}{l}\text { Physical manifestations of } \\
\text { disease states }\end{array}$} & Severe diarrhea as of few days of age & None \\
\hline & PCT: Proximal Convoluted Tubule. SGL & Sodium-glucose co-transporter. \\
\hline
\end{tabular}

(SGLTs) which utilize the $\mathrm{Na}^{+}$-electrochemical gradient provided by the $\mathrm{Na}^{+}-\mathrm{K}^{+}$ATPase pump in order to transport glucose into cells against its concentration gradient [1].

There are six identified SGLTs described, two of which (SGLT1 and SGLT2) are considered to be the most important and are described in Table 1 [2-5]. SGLTs transport glucose across the luminal membrane of the cells lining the small intestine and across the proximal tubules of the kidneys [4]. SGLT2 turned out to be the major one involved in the active transport of glucose against its concentration gradient [5]. SGLT1 is thought to remove most of the remaining luminal glucose in the later sections of the proximal tubule [4-5].

It is well known that diabetes mellitus (DM) is a growing public health concern worldwide. In 2013, the number of patients with type II diabetes mellitus (T2D) was estimated to be $382 \mathrm{mi}-$ Ilion; and by year 2035 this number is expected to rise to 592 million [6]. In addition, a much larger segment of the world's population is diagnosed with pre-diabetes. Pre-diabetes is defined by a blood glucose concentration higher than normal, but not meeting the definition of diabetes per se. The World Health Organization (WHO) defined pre-diabetes as impaired fasting glucose concentration (IFG) ranging between $110 \mathrm{mg} / \mathrm{dl}$ and $126 \mathrm{mg} / \mathrm{dl}$, and/or impaired glucose tolerance (IGT), where the plasma glucose concentration, 2 hours post a $75 \mathrm{~g}$ oral glucose load, ranges between $140 \mathrm{mg} / \mathrm{dl}$ and $199 \mathrm{mg} / \mathrm{dl}$. The American Diabetes Association (ADA) uses the same WHO definition for the post-load threshold values for impaired glucose tolerance but a lower cut-off value for the impaired fasting glucose (100-125 $\mathrm{mg} / \mathrm{dl})$. Furthermore, as per ADA, a glycated hemoglobin (HbA1c) between 5.7 and 6.4\%, can also be used for diagnosing pre-diabetes as well. It is important to note that the ADA and the WHO recognize that an $\mathrm{HbA} 1 \mathrm{c}$ level $\geq 6.5 \%$ is indicative of diabetes [6-9].

Around 316 million people worldwide or around $6.9 \%$ of adults are estimated to have impaired glucose tolerance and by the year 2035, this is even projected to increase to around 471 million, which is around $8.0 \%$ of the total adult population [10]

This review highlights pre-diabetes associated risks and the available treatment options. We also touched on the established role of SGLT2 inhibitors in T2D, further focusing on their potential in reversing pre-diabetes as well as their emerging extraglycemic beneficial effects. 


\section{Health Risks Linked to Pre-diabetes}

The first well-known risk is the progression to T2D. In a meta-analysis, which evaluated the progression to diabetes in these patients, the annual incidence rate of diabetes was found to be between $4 \%-6 \%$ for patients with IGT, 6-9\% for isolated IFG and $15 \%-19 \%$ for both IGT and IFG [11]. Other major studies reported similar increased annual incidence rates of conversion from pre-diabetes to diabetes. Increased risk of chronic kidney disease and early nephropathy was also found to be highly associated with pre-diabetes [12-13]. This association remains unclear but it was hypothesized that it may be due to the increased incidence of diabetes in this group or to the toxic effect of the high glucose level itself [14]. Patients with pre-diabetes were also found to have a higher frequency of idiopathic polyneuropathy, painful sensory neuropathy [1516] and small fiber neuropathy [17-18]. In addition, it was found that around 8 percent of pre-diabetic patients had evidence of diabetic retinopathy [19]. Patients who were diagnosed with pre-diabetes were also found to be at increased risk of developing macro-vascular diseases although the reason for this increased risk is still unclear [20-21]. Aside from the classic complications, studies revealed increased risk of Alzheimer's disease in diabetics, as it makes neurons more vulnerable to amyloid and tau toxicity, and it is now postulated that pre-diabetic patients run the same risk through impaired insulin signaling or resistance [22]. Therefore, it is clear that, it is extremely important not to ignore this subset of patients who are not frankly diabetic but are at increased risk of developing DM.

\section{Current Treatment Options for Patients with Pre-diabetes}

The beneficial effects of lifestyle interventions were confirmed in the two largest diabetes prevention studies, the United States Diabetes Prevention Program (DPP) and the Finnish Diabetes Prevention Study (DPS) [23-24]. In the DPP study, intensive lifestyle interventions (ILS) led to a $58 \%$ risk reduction of diabetes development after a 3-year follow-up [23]. The lifestyle modification in the Finnish DPS consisted of weight reduction more than 5 percent, total fat intake less than 30 percent of energy intake, saturated-fat intake less than 10 percent of energy intake, fiber intake greater than or equal to $15 \mathrm{~g}$ per $1000 \mathrm{kcal}$, and exercise greater than 4 hours per week [24]. This resulted in 9\% DM in the intervention group versus $20 \%$ among the control group over 3 years [24]. Another study showed that for every $1 \mathrm{~kg}$ decrease in weight, the future risk of diabetes development was reduced by $16 \%$ [25].

Several anti-diabetic drugs groups have been studied in context of pre-diabetes. These include biguanides, thiazolidinediones, $\alpha$-glucosidase inhibitors and incretin based therapies [23, 26-33]. The class of drugs mostly linked to decreased incidence of diabetes development in pre-diabetics, were thiazolenediones. In the double-blinded placebo controlled Diabetes Reduction Assessment with Ramipril and rosiglitazone, rosiglitazone was found to decrease the incidence risk of diabetes by $60 \%$ over a 3-year period despite being associated with significant side effects including weight gain and a slightly higher incidence of heart failure $(0.5 \%$ versus $0.1 \%)$ and total cardiovascular events $(2.9 \%$ versus $2.1 \%$ ) [26]. The collective evidence of trials on the role of metformin in patients with IGT suggested a $45 \%$ risk reduction for development of T2D [29]. In a randomized, double-blinded trial of 1,780 Japanese subjects, Voglibose significantly lowered the risk of progression to T2D (hazard ratio: 0.595] and significantly achieved a normal OGTT compared to placebo (hazard ratio 1.539) [30].

Different clinical studies investigated as well the effect of incretin-based therapy in patients with pre-diabetes. A study with vildagliptin showed that it reduced postprandial glucose excursions and improved islet cell function. This was associated with a small but significant reduction in HbA1c levels 
(- 0.15\%, from a baseline of 5.9\%) [31]. Liraglutide was mainly studied in obese and overweight pre-diabetic patients and showed improvement in steady-state plasma glucose concentration [32] and fasting plasma glucose [33].

\section{Efficacy of SGLT2 inhibitors For Patients with T2D and Pre-diabetes}

SGLT2 inhibitors have clearly proven their efficacy in many different placebo-controlled trials in patients with T2D treated with diet and exercise [34-36], and as add-on to other glucose-lowering agents such as metformin [37-40], sulphonylurea [41], pioglitazone [42-43], dipeptidyl peptidase-4 (DPP-4) inhibitor [44], triple oral therapy [44-47], and in combination with insulin [48]. They were also found to be as active; or even more active than other glucose lowering agents (such as sitagliptin) [49].

A review of placebo-controlled randomized clinical trials on SGLT2 inhibitors by Sheen AJ, has shown significant reductions in $\mathrm{HbA} 1 \mathrm{C}$ and a significant lowering of fasting plasma glucose when they were administered as monotherapy or in addition to other glucose-lowering therapies including insulin [50]. Also, in head-to-head trials, SGLT2 inhibitors exerted similar glucose-lowering activity to metformin, sulphonylurea or sitagliptin and the risk of hypoglycaemia was much lower with SGLT2 inhibitors than with sulphonylureas and was similarly low as that reported with metformin, pioglitazone or sitagliptin [50]. Of great importance is that SGLT2 inhibitors were also found to offer added benefit by addressing unmet clinical needs, such as weight loss, lipid and blood pressure control [51-53].

Although SGLT2 inhibitors use sounds promising because of their unique mechanism of action, there is no clear data regarding their use in the prevention of diabetes in pre-diabetic individuals. However animal and human data showed promising effects on improvements in beta cell function. A study on rats reported improvements in beta cell function in those treated with phlorizin, a competitive non- selective inhibitor of both SGLT1 and SGLT2 [54]. Improvements in model-based measures of beta cell function was also observed in mixed meal tolerance tests in subjects treated with empagliflozin [55] and canagliflozin within the first day of treatment and after 6-12 months [56]. In addition, non-statistically significant improvements were observed in the acute insulin response to glucose in subjects treated with dapagliflozin for 3 months, with a significant increase from baseline glucose disappearance rate observed with dapagliflozin [57]. One additional improvement in patients on SGLT2 inhibitors was the peripheral insulin sensitivity. In two hyperinsulinemic-euglycemic clamp studies, ranging from 2 weeks to 3 months, treatment with dapagliflozin was found to increase glucose disposal rate of around $15-20 \%$ relative to placebo [57-58]. Insulin sensitivity was again found to be improved in patients who were treated with empagliflozin and canagliflozin, assessed with the use of mixed-meal tolerance testbased measurements [55-56]

It is obvious that longer and larger studies are needed to assess whether SGLT2 inhibitors slow the progressive decline in b-cell function that occurs in pre-diabetes as they do in patients with diabetes and to translate the above physiologic mechanisms into palpable clinical benefits.

\section{Extra Metabolic Effects of SGLT2 inhibitors A. Protective effects of SGLT2 inhibition on the kid- neys and cardiovascular system}

Hyperglycemia was shown to increase the tubular glucose load, exposure, and reabsorption. Thus, preventing proximal tubule reabsorbtion of glucose through SGLT2 inhibitors may attenuate the detrimental effects of glucose on the diabetic kidney and eventually delay the development of diabetic nephropathy [59-60]. Studies on Akita mice showed that empagliflozin did not prevent but strongly attenuated kidney growth as was shown by reduced molecular markers and reduced inflammation in proportion to hyperglycemia [61]. In another rat mo- 
del study of T2DM, luseogliflozin prevented the fall in GFR and decreased the degree of glomerular injury, renal fibrosis, and tubular necrosis. In addition, in combination with the renin angiotensin system (RAS), SGLT2 inhibition had additive reno-protective effects compared to either drug alone [62].

Recent secondary outcomes results from the EMPA-REG OUTCOME trial on Empagliflozin in patients with T2D at high risk for cardiovascular events were published and revieled that those who received empagliflozin in addition to standard care [RAS inhibitors] had a significantly lower risk of microvascular outcome events than did those receiving placebo, a difference that was driven by a lower risk of progression of kidney disease [63]. In addition, patients in the empagliflozin group also had a significantly lower risk of progression to macroalbuminuria or clinically relevant renal outcomes, such as a doubling of the serum creatinine level and initiation of renal-replacement therapy [63]. The authors postulate that the following mechanisms explain the observed effects: reduction of proximal tubular sodium reabsorption, leading to increase distal sodium delivery to the macula densa thereby activating tubuloglomerular feedback and leading to afferent vasomodulation and a decrease in hyperfiltration, reduction in the intraglomerular pressure as well as other effects on arterial stiffness, vascular resistance, serum uric acid levels, and the systemic and renal neurohormonal systems [63].

All of the above mentioned results clearly indicate that SGLT2 inhibition can reduce diabetic kidney growth, inflammation, and injury despite the high glucose load downstream of the early proximal tubule.

\section{B. Reduction in Blood Pressure}

Due to the fact that SGLT2 inhibition induces a modest glucose-based osmotic diuresis and a small natriuretic effect, a reduction in systolic blood pressure [BP] of around 3-6 mm Hg was noted in patients with DM, which is considered to be comparable to that achieved with other established BP-lowering agents and therefore would be anticipated to have a vascular protective effect specially in high risk patients [64]. A recent review of SGLT2 inhibitors which looked at the blood pressure-lowering effects of dapagliflozin and canagliflozin, in both hypertensive and normotensive patients with T2D, demonstrated a 4-10 $\mathrm{mmHg}$ reduction in systolic blood pressure [65]. Moreover, a large study looked at the effectiveness and safety of empagliflozin on blood pressure reduction, using a 24-h ambulatory blood pressure monitoring, in 800 subjects with T2D whose mean age was 60 years and who had good kidney function but were either normotensive (<140/90 mmHg) or had stage 1 hypertension (blood pressure between 140/90 and 160/99 $\mathrm{mmHg}$ ) [66]. Despite being a co-primary end point, there was a significant reduction in 24-h systolic and diastolic blood pressures; 4 and $2 \mathrm{mmHg}$ respectively, lower than placebo at the high empagliflozin dose (25mg) [66]. The question arises about possible synergistic blood pressure lowering effects when SGLT2 inhibitors are added to other anti-hypertensive classes. In a double-blind, placebo-controlled, phase 3 study on patients with uncontrolled T2D and hypertension receiving a RAS blocker and an additional antihypertensive drug, Dapagliflozin blood pressure-lowering properties were particularly favourable in patients already receiving a beta blocker or calcium-channel blocker [67]. Also, in an investigation that studied patients with T1D treated with empagliflozin 25 mg daily for a period of 8 weeks, significant blood pressure reductions were noted in addition to a significant decrease in radial augmentation index, carotid augmentation index, and aortic augmentation index, with no significant changes in sympathetic nervous system activity measurements [68].

The exact mechanism of blood pressure lowering with these agents is not completely understood; however, is assumed to be related to its osmotic diuretic effect. They also have a very slight natriuretic effect, much less when compared to low-dose 
thiazides. Weight loss may also be a contributing mechanism although the blood pressure effect is seen much earlier than the weight loss effect.

\section{Weight Loss}

Treatment with SGLT2 inhibitors was also found to offer weight loss benefits in overweight/obese patients with T2D [69]. In a meta-analysis of 12 randomized-controlled trials, dapagliflozin was found to cause a statistical significant $2.10 \mathrm{~kg}$ weight loss, while in another one, dapagliflozin treatment was also associated with a significant reduction in body weight of $1.63 \mathrm{~kg}$ [70-71]. It is primordial to differentiate between water and fat loss. Dapagliflozin was shown to cause a reduction in total body weight, predominantly by reducing fat mass, visceral adipose tissue and subcutaneous adipose tissue in T2D inadequately controlled with metformin, at 24 weeks [72]. These findings were again confirmed over a period of 102 weeks, where dapagliflozin was shown to improve glycemic control, and reduced weight and fat mass [73]. This weight loss effect was associated with improvement in overall healthrelated quality of life [74].

In a meta-analysis of ten trials, another SGLT 2 inhibitor, canagliflozin was found to cause greater body weight loss when compared to placebo (weight mean difference of $2.81 \mathrm{~kg}$ ), especially with the $300 \mathrm{mg} /$ day dose which was found to be superior in terms of weight loss reduction to $100 \mathrm{mg} /$ day in all trials [75]. In another trial, it was shown that canagliflozin-associated weight reduction also offers some advantages over sitagliptin, which was weight-neutral [76]. Also a phase II study evaluated the effects of canagliflozin on body weight in overweight and obese individuals without diabetes and it was shown that it significantly reduced body weight compared with placebo, with a least squares mean percent changes from baseline of $22.2 \%, 22.9 \%, 22.7 \%$, and $21.3 \%$ with canagliflozin 50, 100, and $300 \mathrm{mg}$ and placebo [77]. A slightly greater reduction in visceral adipose tissue than in subcutaneous adipose tissue was found upon analysis of abdominal fat in the canagliflozin groups with computed tomography imaging [78].

Just in accordance with other SGLT 2 inhibitors, empagliflozin was associated with modest but significant body weight loss (WMD $-1.84 \mathrm{~kg}$ vs -1.38 $\mathrm{kg}$ in placebo), in a meta-analysis of ten randomized controlled trials but with no obvious weight loss difference between 10 and $25 \mathrm{mg}$ in the various trials [79]. Empagliflozin-associated weight loss contrasted with the weight gain induced by a sulphonylurea [80] and the weight neutrality observed with sitagliptin [81]. There are no available data on body composition with empagliflozin.

\section{Conclusion}

The role of SGLT-2 inhibitors in pre-diabetic patients should definitely be better assessed and evaluated as data has been very promising in patients with T2D and the potential benefits are backed up by plausible physiologic mechanisms.

Moreover SGLT 2 inhibitors were found to have multiple extra-glycemic effects, including weight loss, blood pressure reduction and possibly beneficial effect on the kidneys and prevention of the dreaded microvacular complications.

\section{References}

1. Wood S, Trayhurn P. Glucose transporters (GLUT and SGLT): expanded families of sugar transport proteins. British Journal of Nutrition. 2003; 89: 3-9.

2. Kanai Y, Lee WS, You G, Brown D \& Hediger MA. The human kidney low affinity $\mathrm{Na}^{+}$/glucose cotransporter SGLT2. Delineation of the major renal reabsorptive mechanism for Dglucose. Journal of Clinical Investigation 1994; 93: 397-404.

3. Houseknecht K, Katz EB \& Charron MJ (1997) GLUT4 heterozygous knockout mice develop muscle insulin resistance and diabetes. Nature Medicine 1997; 3: 1096-1101.

4. Wright EM1, Loo DD, Hirayama BA. Biology of human sodium glucose transporters. Physiol Rev. 2011;91(2):733-94.

5. Wells RG, Mohandas TK, Hediger MA. Localization of the $\mathrm{Na}^{+}$/ glucose cotransporter gene SGLT2 to human chromosome 16 close to the centromere. Genomics 1993; 17 (3): 787-9. 
6. American Diabetes Association. Standards of medical care in diabetes-2013. Diabetes Care. 2013; 35: S11-S63.

7. The International Expert Committee. International expert committee report on the role of the A1c assay in the diagnosis of diabetes. Diabetes Care. 2009; 32: 1327-1334.

8. WHO. Use of glycated haemoglobin ( $\mathrm{HbA1c}$ ) in the diagnosis of diabetes mellitus. Diabetes Res. Clin. Pract. 2011; 93: 299-309

9. Report of a WHO/IDF Consultation: Definition and Diagnosis of Diabetes Mellitus and Intermediate Hypergly cemia. WHO, Geneva; 2006. http://whqlibdoc.who.int/ publications/2006/924159 4934 eng.pdf

10. IDF DIABETES ATLAS Sixth edition. Online version of IDF Diabetes Atlas: www.idf.org/diabetesatlas. ISBN:2-930229-85-3.

11. Gerstein HC, Santaguida P, Raina P, Morrison KM, Balion C, Hunt D, Yazdi H, Booker L. Annual incidence and relative risk of diabetes in people with various categories of dysglycemia: a systematic overview and meta-analysis of prospective studies. Diabetes Res Clin Pract. 2007; 78(3):305-12.

12. Gabir MM, Hanson RL, Dabelea D, Imperatore G, Roumain J, Bennett PH, Knowler WC. Plasma glucose and prediction of microvascular disease and mortality: evaluation of 1997 American Diabetes Association and 1999 World Health Organization criteria for diagnosis of diabetes. Diabetes Care. 2000; 23(8):1113-8.

13. Xu M, Li XY, Wang JG, Wang XJ, Huang Y, Cheng Q, Huang HE, Li R, Xiang J, Tan JR, Dai M, Ning G. Retinol-binding protein 4 is associated with impaired glucose regulation and microalbuminuria in a Chinese population. Diabetologia. 2009; 52(8):1511-9

14. Fox CS, Larson MG, Leip EP, Meigs JB, Wilson PW, Levy D. Glycemic status and development of kidney disease: the Framingham Heart Study. Diabetes Care. 2005; 28(10):2436-40.

15. Hoffman-Snyder C, Smith BE, Ross MA, Hernandez J, Bosch $E P$. Value of the oral glucose tolerance test in the evaluation of chronic idiopathic axonal polyneuropathy. Arch Neurol. 2006; 63(8):1075-9.

16. Sumner CJ, Sheth S, Griffin JW, Cornblath DR, Polydefkis M. The spectrum of neuropathy in diabetes and impaired glucose tolerance. Neurology. 2003;14; 60(1):108-11.

17. Singleton JR, Smith AG, Bromberg MB. Increased prevalence of impaired glucose tolerance in patients with painful sensory neuropathy. Diabetes Care. 2001; 24(8):1448-53.

18. Smith AG, Ramachandran $P$, Tripp $S$, Singleton JR. Epidermal nerve innervation in impaired glucose tolerance and diabetesassociated neuropathy. Neurology. 2001; 57(9):1701-4.

19. The prevalence of retinopathy in impaired glucose tolerance and recent-onset diabetes in the Diabetes Prevention Program. Diabetes Prevention Program Research Group Diabet Med. 2007; 24(2):137-44.

20. Emerging Risk Factors Collaboration, Sarwar N, Gao P, Seshasai SR, Gobin R, Kaptoge S, Di Angelantonio E, Ingelsson E, Lawlor DA, Selvin E, Stampfer M, Stehouwer CD, Lewington S, Pennells L, Thompson A, Sattar N, White IR, Ray KK, Danesh J. Diabetes mellitus, fasting blood glucose concentration, and risk of vascular disease: a collaborative meta-analysis of 102 prospective studies. Lancet. 2010; 375(9733):2215-22.
21. Barr EL, Zimmet PZ, Welborn TA, Jolley D, Magliano DJ, Dunstan DW, Cameron AJ, Dwyer T, Taylor HR, Tonkin AM, Wong TY, McNeil J, Shaw JE. Risk of cardiovascular and all-cause mortality in individuals with diabetes mellitus, impaired fasting glucose, and impaired glucose tolerance: the Australian Diabetes, Obesity, and Lifestyle Study (AusDiab). Circulation. 2007; 116(2):151-7.

22. Rapaka D, Bitra V, Akula A. Prediabetes and alzheimer's disease. Indian Journal of Pharmaceutical Sciences. 2015;77(5):511. doi:10.4103/0250-474x.169026.

23. Knowler WC, Barrett-Connor E, Fowler SE, Hamman RF, Lachin JM, Walker EA, Nathan DM, Diabetes Prevention Program Research Group. Reduction in the incidence of type 2 diabetes with lifestyle intervention or metformin. N Engl J Med. 2002; 346(6):393-403.

24. Tuomilehto J, Lindström J, Eriksson JG, Valle TT, Hämäläinen $H$, llanne-Parikka $P$, Keinänen-Kiukaanniemi $S$, Laakso $M$, Louheranta A, Rastas M, Salminen V, Uusitupa M, Finnish Diabetes Prevention Study Group. Prevention of type 2 diabetes mellitus by changes in lifestyle among subjects with impaired glucose tolerance. N Engl J Med. 2001; 344(18):1343-50.

25. Hamman RF, Wing RR, Edelstein SL, Lachin JM, Bray GA, Delahanty L, Hoskin M, Kriska AM, Mayer-Davis EJ, Pi-Sunyer $X$, Regensteiner J, Venditti B, Wylie-Rosett J. Effect of weight loss with lifestyle intervention on risk of diabetes. Diabetes Care. 2006; 29(9):2102-7.

26. DREAM Trial Investigators, Dagenais GR, Gerstein HC, Holman R, Budaj A, Escalante A, Hedner T, Keltai M, Lonn E, McFarlane S, McQueen M, Teo K, Sheridan P, Bosch J, Pogue J, Yusuf S. Effects of ramipril and rosiglitazone on cardiovascular and renal outcomes in people with impaired glucose tolerance or impaired fasting glucose: results of the Diabetes REduction Assessment with ramipril and rosiglitazone Medication (DREAM) trial. Diabetes Care. 2008; 31(5):1007-14.

27. DeFronzo RA, Tripathy D, Schwenke DC, Banerji M, Bray GA, Buchanan TA, Clement SC, Henry RR, Hodis HN, Kitabchi AE, Mack WJ, Mudaliar S, Ratner RE, Williams K, Stentz FB, Musi N, Reaven PD, ACT NOW Study. Pioglitazone for diabetes prevention in impaired glucose tolerance. N Engl J Med. 2011; 364(12):1104-15.

28. Ahmadieh H. Azar S.T. The role of incretin-based therapies in prediabetes: A review. Primary care diabetes 2014; 8: 286-294.

29. Lily M, Godwin M. Treating prediabetes with metformin: systematic review and meta-analysis. Can Fam Physician. 2009; 55(4):363-9.

30. Kawamori R, Tajima N, Iwamoto Y, Kashiwagi A, Shimamoto K, Kaku K. Voglibose for prevention of type 2 diabetes mellitus: a randomised, double-blind trial in Japanese individuals with impaired glucose tolerance. The Lancet. 2009;373(9675):16071614. doi:10.1016/s0140-6736(09)60222-1.

31. J. Rosenstock, J. Foley, M. Rendell, et al., Effects of the dipeptidyl peptidase-IV inhibitor vildagliptin on incretin hormones, islet function, and postprandial glycemia in subjects with impaired glucose tolerance, Diabetes Care 2008; 31: 30-35.

32. Kim S, Abbasi F, Lamendola $C$ et al. Benefits of Liraglutide Treatment in Overweight and Obese Older Individuals With Prediabetes. Diabetes Care. 2013;36(10):3276-3282. 
33. Ariel D, Kim S, Abbasi F, Lamendola C, Liu A, Reaven G. Effect of liraglutide administration and a calorie-restricted diet on lipoprotein profile in overweight/obese persons with prediabetes. Nutrition, Metabolism and Cardiovascular Diseases. 2014;24(12):1317-1322.

34. Ferrannini E, Ramos SJ, Salsali A, et al. Dapagliflozin monotherapy in type 2 diabetic patients with inadequate glycemic control by diet and exercise: a randomized, double-blind, placebocontrolled, phase 3 trial. Diabetes Care. 2010;33(10):2217-24.

35. Bailey CJ, Iqbal N, T'Joen C, et al. Dapagliflozin monotherapy in drug-naive patients with diabetes: a randomized-controlled trial of low-dose range. Diabetes Obes Metab. 2012;14(10):951-9.

36. Kaku K, Kiyosue A, Inoue S, et al. Efficacy and safety of dapagliflozin monotherapy in Japanese patients with type 2 diabetes inadequately controlled by diet and exercise. Diabetes Obes Metab. 2014;16(11):1102-10

37. Bailey CJ, Gross JL, Pieters A, et al. Effect of dapagliflozin in patients with type 2 diabetes who have inadequate glycaemic control with metformin: a randomised, double-blind, placebo controlled trial. Lancet. 2010;375(9733):2223-33.

38. Henry RR, Murray AV, Marmolejo MH, et al. Dapagliflozin, metformin $X R$, or both: initial pharmacotherapy for type 2 diabetes, a randomised controlled trial. Int J Clin Pract. 2012;66(5):446-56.

39. Rosenstock J, Seman LJ, Jelaska A, et al. Efficacy and safety of empagliflozin, a sodium glucose cotransporter 2 (SGLT2) inhibitor, as add-on to metformin in type 2 diabetes with mild hyperglycaemia. Diabetes Obes Metab. 2013;15(12):1154-60.

40. Haring HU, Merker L, Seewaldt-Becker E, et al. Empagliflozin as add-on to metformin in patients with type 2 diabetes: a 24-week, randomized, double-blind, placebo-controlled trial. Diabetes Care. 2014;37(6):1650-9.

41. Strojek K, Yoon $\mathrm{KH}$, Hruba $\mathrm{V}$, et al. Effect of dapagliflozin in patients with type 2 diabetes who have inadequate glycaemic control with glimepiride: a randomized, 24-week, double-blind, placebo-controlled trial. Diabetes Obes Metab. 2011;13(10):92838.

42. Rosenstock J, Vico M, Wei L, et al. Effects of dapagliflozin, an SGLT2 inhibitor, on $\mathrm{HbA}(1 \mathrm{c})$, body weight, and hypoglycemia risk in patients with type 2 diabetes inadequately controlled on pioglitazone monotherapy. Diabetes Care. 2012;35(7):1473-8.

43. Kovacs CS, Seshiah V, Swallow R, et al. Empagliflozin improves glycaemic and weight control as add-on therapy to pioglitazone or pioglitazone plus metformin in patients with type 2 diabetes: a 24-week, randomized, placebo-controlled trial. Diabetes Obes Metab. 2014;16(2):147-58.

44. Jabbour SA, Hardy E, Sugg J, et al. Dapagliflozin is effective as add-on therapy to sitagliptin with or without metformin: a 24-week, multicenter, randomized, double-blind, placebocontrolled study. Diabetes Care. 2014;37(3):740-50.

45. Haring HU, Merker L, Seewaldt-Becker E, et al. Empagliflozin as add-on to metformin plus sulfonylurea in patients with type 2 diabetes: a 24-week, randomized, double-blind, placebocontrolled trial. Diabetes Care. Diabetes Care 2014;37:14801483
46. Wilding JP, Charpentier G, Hollander P, et al. Efficacy and safety of canagliflozin in patients with type 2 diabetes mellitus inadequately controlled with metformin and sulphonylurea: a randomised trial. Int J Clin Pract. 2013;67(12):126782.2013;36(11):3396-404.

47. Forst T, Guthrie R, Goldenberg R, et al. Efficacy and safety of canagliflozin over 52 weeks in patients with type 2 diabetes on background metformin and pioglitazone. Diabetes Obes Metab. 2014;16(5):467-77.

48. Rosenstock J, Jelaska A, Frappin G, et al. Improved glucose control with weight loss, lower insulin doses, and no increased hypoglycemia with empagliflozin added to titrated multiple daily injections of insulin in obese inadequately controlled type 2 diabetes. Diabetes Care. 2014;37(7):1815-23.

49. Roden M, Weng J, Eilbracht J, et al. Empagliflozin monotherapy in drug-narve patients with type 2 diabetes: a randomised, 24-week, double-blind, placebo-controlled, parallel group, trial with sitagliptin as active comparator. Lancet Diabetes Endocrinol. 2013;1(3):208-19.

50. Scheen A.J. Pharmacodynamics, Efficacy and Safety of SodiumGlucose Co-Transporter Type 2 (SGLT2) Inhibitors for the Treatment of Type 2 Diabetes Mellitus. Drugs. 2015; 75:33-59.

51. Liakos A, Karagiannis T, Athanasiadou E, et al. Efficacy and safety of empagliflozin for type 2 diabetes: a systematic review and meta-analysis. Diabetes Obes Metab. 2014;16(10):984-93.

52. Yang $X P$, Lai $D$, Zhong $X Y$, et al. Efficacy and safety of canagliflozin in subjects with type 2 diabetes: systematic review and meta-analysis. Eur J Clin Pharmacol. 2014;70(10):1149-58.

53. Lambers Heerspink HJ, de Zeeuw D, Wie L, et al. Dapagliflozin a glucose-regulating drug with diuretic properties in subjects with type 2 diabetes. Diabetes Obes Metab. 2013; 15 (9):853-62.

54. Brichard S.M. Henquin J.C. Girard J. Phlorizin treatment of diabetic rats partially reverses the abnormal expression of genes involved in hepatic glucose metabolism. Diabetologia 1993; 36 (4): 292-298

55. Ferrannini E, Muscelli E, Frascerra S, et al. Metabolic response to sodium-glucose cotransporter 2 inhibition in type 2 diabetic patients. J Clin Invest 2014;124:499-508.

56. Polidori D,Mari A, Ferrannini E. Canagliflozin, a sodium glucose co-transporter 2 inhibitor, improves model-based indices of beta cell function in patients with type 2 diabetes. Diabetologia 2014;57:891-901.

57. Mudaliar S, Henry RR, Boden G, et al. Changes in insulin sensitivity and insulin secretion with the sodium glucose cotransporter 2 inhibitor dapagliflozin. Diabetes Technol Ther 2014;16:137-144.

58. Merovci A, Solis-Herrera C, Daniele G, et al. Dapagliflozin improves muscle insulin sensitivity but enhances endogenous glucose production. J Clin Invest 2014;124:509-514.

59. Vallon V, Thomson SC. 2012. Renal function in diabetic disease models: the tubular system in the pathophysiology of the diabetic kidney. Annu. Rev. Physiol. 74:351-75.

60. Vallon V. 2011. The proximal tubule in the pathophysiology of the diabetic kidney. Am. J. Physiol. Regul. Integr. Comp. Physiol. 300:R1009-R1022. 
61. Vallon V, Gerasimova M, Rose MA, et al. 2014. SGLT2 inhibitor empagliflozin reduces renal growth and albuminuria in proportion to hyperglycemia and prevents glomerular hyperfiltration in diabetic Akita mice. Am. J. Physiol. Ren. Physiol. 306:F194-F204.

62. Kojima N, Williams JM, Takahashi T, et al. 2013. Effects of a new SGLT2 inhibitor, luseogliflozin, on diabetic nephropathy in T2DN rats. J. Pharmacol. Exp. Ther. 345:464-72.

63. Wanner C, Inzucchi SE, Lachin JM, et al. Empagliflozin and Progression of Kidney Disease in Type 2 Diabetes. New England Journal of Medicine N Engl J Med. 2016. doi:10.1056/ nejmoa1515920

64. Foote C, Perkovic V,Neal B. 2012. Effects of SGLT2 inhibitors on cardiovascular outcomes. Diab. Vasc. Dis. Res. 9:117-23.

65. Oliva RV, Bakris GL. Blood pressure effects of sodium-glucose cotransport 2 (SGLT2) inhibitors. J Am Soc Hypertens 2014;8:330339.

66. Tikkanen I, Narko K, Zeller C, et al.; EMPAREG BP Investigators. Empagliflozin reduces blood pressure in patients with type 2 diabetes and hypertension. Diabetes Care 2015;38: 420-428.

67. Weber MA, Mansfield TA, Cain VA, Iqbal N, Parikh S, Ptaszynska A. Blood pressure and glycaemic effects of dapagliflozin versus placebo in patients with type 2 diabetes on combination antihypertensive therapy: a randomised, double-blind, placebocontrolled, phase 3 study. The Lancet Diabetes \& Endocrinology. 2016;4(3):211-220. doi:10.1016/s2213-8587(15)00417-9.

68. Cherney DZ, Perkins BA, Soleymanlou N, Har R, Fagan N, Johansen O.E, Woerle H-J, Eynatten M.V, Broedl U.C. The effect of empagliflozin on arterial stiffness and heart rate variability in subjects with uncomplicated type 1 diabetes mellitus. Cardiovasc Diabetol 2014;13:28.

69. Barnett AH. Impact of sodium glucose cotransporter 2 inhibitors on weight in patients with type 2 diabetes mellitus. Postgrad Med. 2013;125(5):92-100.

70. Sun YN, Zhou Y, Chen $X$, et al. The efficacy of dapagliflozin combined with hypoglycaemic drugs in treating type 2 diabetes mellitus: meta-analysis of randomised controlled trials. BMJ Open. 2014;4(4):e004619.

71. Zhang $M$, Zhang $L$, Wu B , et al. Dapagliflozin treatment for type diabetes: a systematic review and meta-analysis of randomized controlled trials. Diabetes Metab Res Rev. 2014;30(3):204-21.

72. Bolinder J, Ljunggren $\mathrm{O}$, Kullberg J, et al. Effects of dapagliflozin on body weight, total fat mass, and regional adipose tissue distribution in patients with type 2 diabetes mellitus with inadequate glycemic control on metformin. J Clin Endocrinol Metab. 2012;97(3):1020-31.

73. Bolinder J, Ljunggren O, Johansson L, et al. Dapagliflozin maintains glycaemic control while reducing weight and body fat mass over 2 years in patients with type 2 diabetes mellitus inadequately controlled on metformin. Diabetes Obes Metab. 2014;16(2):159-69.

74. Grandy S, Hashemi M, Langkilde AM, et al. Changes in weight loss-related quality of life among type 2 diabetes mellitus patients treated with dapagliflozin. Diabetes Obes Metab. 2014;16(7):645-50.
75. Yang $X P$, Lai $D$, Zhong $X Y$, et al. Efficacy and safety of canagliflozin in subjects with type 2 diabetes: systematic review and meta-analysis. Eur J Clin Pharmacol. 2014;70(10):1149-58.

76. Schernthaner G, Gross JL, Rosenstock J, et al. Canagliflozin compared with sitagliptin for patients with type 2 diabetes who do not have adequate glycemic control with metformin plus sulfonylurea: a 52-week randomized trial. Diabetes Care. 2013;36(9):2508-15.

77. Bays HE, Weinstein R, Law G, Canovatchel W. Canagliflozin: Effects in Overweight and Obese Subjects Without Diabetes Mellitus. Obesity (2014) 22, 1042-1049. doi:10.1002/oby.20663

78. Cefalu WT, Leiter LA, Yoon KH, et al. Efficacy and safety of canagliflozin versus glimepiride in patients with type 2 diabetes inadequately controlled with metformin (CANTATA-SU): 52 week results from a randomised, double-blind, phase 3 noninferiority trial. Lancet. 2013;382(9896):941-50.

79. Liakos A, Karagiannis T, Athanasiadou E, et al. Efficacy and safety of empagliflozin for type 2 diabetes: a systematic review and meta-analysis. Diabetes Obes Metab. 2014;16(10):984-93.

80. Ridderstrale $M$, Andersen KR, Zeller $C$, et al. Comparison of empagliflozin and glimepiride as add-on to metformin in patients with type 2 diabetes: a 104-week randomised, activecontrolled, double-blind, phase 3 trial. Lancet Diabetes Endocrinol. 2014;2(9):691-700.

81. Ferrannini $E$, Berk $A$, Hantel $S$, et al. Long-term safety and efficacy of empagliflozin, sitagliptin, and metformin: an activecontrolled, parallel-group, randomized, 78-week openlabel extension study in patients with type 2 diabetes. Diabetes Care. 2013;36(12):4015-21.

\section{Publish in International Archives of Medicine}

International Archives of Medicine is an open access journal publishing articles encompassing all aspects of medical science and clinical practice. IAM is considered a megajournal with independent sections on all areas of medicine. IAM is a really international journal with authors and board members from all around the world. The journal is widely indexed and classified Q2 in category Medicine. 